\title{
Household Survey assessing Impact of Safe Abortion and Contraception Interventions in Cambodia
}

\author{
Sarah Bandali ${ }^{1 *}$, Elizabeth Lavoisier ${ }^{2}$ and Ramji Dhakal ${ }^{1,3}$ \\ ${ }^{1}$ Options Consultancy Services, $U K$ \\ ${ }^{2}$ Gender and Health Innovations, Cambodia
}

${ }^{3}$ SBK Research and Development, Phnom Penh, Cambodia

Submission: June 25, 2018; Published: July 27, 2018

*Corresponding author: Sarah Bandali, Options Consultancy Services Ltd, 2nd Floor, St Magnus House | 3 Lower Thames Street | London EC3R 6HD, UK, Tel: +44 (0)20 7430 1900; Email: s.bandali@options.co.uk

\section{Abstract}

Introduction: The Government of Cambodia with support from the Reduction in Maternal Mortality Project (RMMP) helped improve access to safe abortion and long-term contraceptive services for women.

Methods: A cross sectional household survey was conducted with 1,680 women of reproductive age in six Cambodian provinces to assess the impact of RMMP service provision and community awareness interventions.

Results: More women are using a contraceptive method in the intervention arms than in the control arm $(\mathrm{p}<0.001)$. Significantly more women reported receiving advice from a provider on contraceptive use in the intervention arms (76\%) compared to the control arm (67\%), $(\mathrm{p}<0.05)$. More women know that abortion is legal in intervention arms $(24 \%)$ than in the control arm $(7 \%),(p<0.001)$. On average, $96 \%$ of women know that the safest time for an abortion is during the first trimester. The percentage of respondents who thought abortion was legal in cases of rape or incest is significantly higher in the intervention arms ( $\mathrm{p}<0.001)$, at $53 \%$ on average compared to the control arm $(36 \%)$. More women in the intervention arms were referred for a contraceptive method after the last abortion ( $75 \%$ on average) compared with $50 \%$ in the control arm.

Conclusion: There are significant differences in provinces where service provision and community awareness raising activities were implemented in terms of knowledge, access to and use of safe abortion and long-term contraception services. The combined interventions can help improve the health and well-being of Cambodian women and help the country achieve progress towards its Sustainable Development Goals.

Keywords: Contraceptive method; Abortion; knowledge, attitude and practice survey; Service delivery; Contraception; Sterilization; Training and community awareness; Pregnancy; Manual vacuum aspiration; Injectables; Medical abortion; Curettage; Sustainable Development Goals

Abbreviations: RMMP: Reduction in Maternal Mortality Project; RMNCH: Reproductive, Maternal, Newborn and Child Health; KAP: Knowledge, Attitudes and Practices; MVA: Manual Vacuum Aspiration

\section{Introduction}

Cambodia has made significant progress in improving the health of women and children. Since the 1990s, strong political will combined with evidence-based policies have advanced reproductive, maternal, newborn and child health (RMNCH) outcomes including among others: improved access to contraceptive services and the legalization of abortion [1]. The pro-natalist policies in Cambodia between 1971-1991, encouraging families to have many children and increase population size were reversed [2]. A birth spacing policy was implemented in
1995, which lead to substantial improvements in access to and use of contraceptive methods. As a result of such policies, there is almost universal knowledge of modern contraceptive methods among women, and the use of modern methods of contraception continues to increase from 19\% in 2000 to $39 \%$ in 2014 [3].

In 1997, abortion was legalized (up to the 12th week of pregnancy). The law is one of the most liberal in Asia; however, safe abortion services were limited until wider roll-out kickstarted in 2005 with the help of external partners [4]. Health- 
care providers in public and private facilities were trained on safe abortion and, in 2010, medical abortion was endorsed by the government. As a result, more women now have access to safe abortion services, with noted declines in maternal deaths resulting from unsafe abortion [5]. According to the 2014 Demographic and Health Survey[3], 12\% of women in Cambodia aged 15-49 years of age reported having one or more abortions in their lifetime. Most women (60\%) had an abortion in a health facility, with the majority going to the private sector. Women who had an abortion from a qualified health care provider decreased over time from $79 \%$ in 2005 to $61 \%$ in 2014 . The proportion of women who did not receive any assistance in their last abortion rose from $8 \%$ in 2005 to $30 \%$ in 2014 indicating that an increasing number of women are not accessing safe abortion services.

The Reduction in Maternal Mortality Project (RMMP) was implemented over a three year period to support the Government of Cambodia's efforts in providing quality safe abortion and contraceptive services. RMMP's support to service provision included capacity building of service providers and trainers; quality assurance visits; application of clinical guidelines and protocols and case reviews of critical clinical incidents. Complementing service provision interventions, RMMP improved community awareness, promoting messages on safe abortion and access to contraception. A household survey was conducted with 1,680 women in six provinces of Cambodia to assess the impact of RMMP service provision and community awareness interventions for wider learning within Cambodia and beyond [6].

\section{Methods}

A cross sectional household survey was implemented in six provinces: Takeo, Kampong Thom, Prey Veng, Siem Reap, Pursat and Kampong Som. Data was collected using a knowledge, attitudes and practices (KAP) questionnaire focused on abortion and modern contraceptive methods. The study populations were female household members of reproductive age (15-49 years). A sample size of 1,680 was appropriate for measuring KAP variables in the selected communities and allowed for comparisons between the different provinces with a power of $>80 \%$ and with a significance level of 0.05 , taking into account the design effect of 1.34. A total of 42 clusters were therefore surveyed: Seven villages in each of the six selected provinces. In each cluster, 40 questionnaires were administered among women residents of randomly selected households. The respondents were selected using a two-stage cluster sampling method. The first stage of sampling consisted of a random selection of the clusters in 6 provinces where interventions were implemented.

\section{Service Delivery Arm}

Siem Reap and Prey Veng provinces only service provision interventions were implemented

\section{Combined Intervention Arm}

Takeo and Kampong Thom provinces where both community awareness and service provision interventions were implemented.

\section{Control Arm}

Sihanoukville and Pursat provinces where RMMP was not present and where no providers were trained on safe abortion practices

The second stage was the selection of households where the WHO random walk approach was used. Comparisons were made between the two intervention arms (service delivery and combined interventions) and between each intervention arm and the control arm. Descriptive statistics were used to measure KAP. A chi-square test was used for comparison between intervention and control clusters of households. To identify predictors of safe abortion practices, univariate and multivariate analyses were performed using logistic regressions.

\section{Results}

\section{Profile of respondents}

There was no significant difference in the profile of respondents in the three arms. The average age of women interviewed was 30 years. Seventy-three percent of women had already experienced a pregnancy. Sixty-seven percent of respondents were married and living with their husband or living with a man as married. Eleven percent of them had an abortion, $27 \%$ of them had more than one.

\section{Knowledge attitude and practice related to contracep- tives}

Ninety-eight percent of respondents knew at least one method of contraception. The daily pill was most cited and significantly higher in the combined intervention arm (93\%) than in the service provision and control arms (88\%). Injectables were the second most cited method (77\%) and was significantly higher in the service delivery arm (82\%) than in other arms (75\%). Sixteen percent of the women interviewed knew about female sterilization. The percentage is significantly higher among women in the two intervention arms (19\%) than in the control arm (10\%)

\section{Use of contraceptive methods}

Twenty seven percent of the women do not have their family planning needs met and $21 \%$ stated that their last pregnancy was unwanted; there is no significant difference between the three arms. Thirty-five percent of respondents indicated they are currently using a contraceptive method (Table 1). $41 \%$ in the combined intervention arm, $36 \%$ in the service delivery arm and $28 \%$ in the control arm $(\mathrm{p}<0.001)$. More women in the intervention arms (64\%) received their contraceptive method at the health center compared to the control arm $(55 \%)(p<0.001)$.

\section{Contraception services provided by health staff}

In the intervention arms, more women reported receiving advice from a provider on contraceptive use (76\%) compared to the control arm $(67 \%),(p<0.05)$. Also, in the intervention arms, a higher percentage of women reported receiving information on alternative methods $(66 \%)$ than in the control arm (45\%), $(\mathrm{p}<0.001)$. 


\section{Global Journal of Reproductive Medicine}

Table 1: Current Use of Contraceptive Method

\begin{tabular}{|c|c|c|c|c|c|c|c|c|c|c|c|}
\hline \multirow{3}{*}{\begin{tabular}{|c|} 
Category \\
Methods currently used
\end{tabular}} & \multirow{2}{*}{\multicolumn{2}{|c|}{$\begin{array}{c}\text { Total } \\
6 \text { provinces }\end{array}$}} & \multirow{2}{*}{\multicolumn{2}{|c|}{\begin{tabular}{|c} 
Control Arm \\
$\begin{array}{c}\text { Kampong Som / } \\
\text { Pursat }\end{array}$
\end{tabular}}} & \multirow{2}{*}{\multicolumn{2}{|c|}{$\begin{array}{c}\text { Service Delivery } \\
\text { (Arm A) }\end{array}$}} & \multirow{2}{*}{\multicolumn{2}{|c|}{$\begin{array}{c}\begin{array}{c}\text { Combined } \\
\text { Intervention } \\
\text { (Arm B) }\end{array} \\
\begin{array}{c}\text { Takeo / } \\
\text { Kampong Thom }\end{array}\end{array}$}} & \multicolumn{3}{|c|}{ Comparison tests } \\
\hline & & & & & & & & & \multirow[t]{2}{*}{$\begin{array}{l}\text { Control vs. } \\
\text { Arm A }\end{array}$} & \multirow[t]{2}{*}{$\begin{array}{l}\text { Control } \\
\text { vs. Arm } \\
\text { B }\end{array}$} & \multirow[t]{2}{*}{$\begin{array}{c}\text { Arm A } \\
\text { vs. Arm } \\
\text { B }\end{array}$} \\
\hline & $N=586$ & $\%$ & $N=156$ & $\%$ & $N=201$ & $\%$ & $N=228$ & $\%$ & & & \\
\hline $\begin{array}{l}\text { Women currently on } \\
\text { contraceptive method }\end{array}$ & 586 & 34.9 & 157 & 28 & 200 & 35.7 & 229 & 40.9 & $\mathrm{p}=0.006$ & $\mathrm{p}<0.001$ & $\mathrm{p}=0.04$ \\
\hline $\begin{array}{l}\text { Married or with live-in } \\
\text { partner }\end{array}$ & 552 & 49 & 145 & 41.3 & 189 & 50.6 & 218 & 54.2 & $\mathrm{p}=0.01$ & $\mathrm{p}<0.001$ & NS \\
\hline $\begin{array}{l}\text { Single, widowed, } \\
\text { divorced }\end{array}$ & 34 & 6.1 & 12 & 5.7 & 11 & 5.9 & 11 & 7 & NS & NS & NS \\
\hline Aged under 25 & 87 & 14.8 & 28 & 14.5 & 33 & 19.6 & 26 & 16.8 & NS & NS & NS \\
\hline $\begin{array}{c}\text { Aged between } 25 \text { and } \\
34\end{array}$ & 243 & 41.5 & 58 & 32.4 & 89 & 45.2 & 96 & 48.5 & $\mathrm{p}=0.01$ & $\mathrm{p}=0.002$ & NS \\
\hline Aged 35 and over & 256 & 43.7 & 71 & 37.7 & 78 & 40 & 107 & 51.4 & NS & $\mathrm{p}=0.006$ & $\mathrm{p}=0.02$ \\
\hline \multicolumn{12}{|c|}{ Methods currently used } \\
\hline Daily pill & 176 & 30.1 & 59 & 37.8 & 46 & 22.9 & 71 & 31.1 & $\mathrm{p}=0.002$ & NS & $\mathrm{p}=0.003$ \\
\hline Injectables & 170 & 29.1 & 37 & 23.7 & 62 & 30.9 & 71 & 31.1 & NS & NS & NS \\
\hline Withdrawal & 82 & 14 & 14 & 9 & 31 & 15.4 & 37 & 16.2 & $\mathrm{NS}(\mathrm{p}=0.07)$ & $\mathrm{p}=0.04$ & NS \\
\hline Rhythm method & 37 & 6.3 & 16 & 10.3 & 8 & 4 & 13 & 5.7 & $p=0.02$ & NS & NS \\
\hline IUD & 52 & 8.9 & 6 & 3.9 & 28 & 13.9 & 18 & 7.9 & $\mathrm{p}=0.003$ & NS & $\mathrm{p}=0.03$ \\
\hline Condoms & 37 & 6.3 & 16 & 10.3 & 12 & 6 & 9 & 4 & NS & $\mathrm{p}=0.01$ & NS \\
\hline Female sterilization & 18 & 2.9 & 6 & 3.7 & 7 & 3.3 & 5 & 2.1 & NS & NS & NS \\
\hline Lactation method & 9 & 1.5 & 1 & 0.7 & 3 & 1.5 & 5 & 2.2 & NS & NS & NS \\
\hline Implants & 8 & 1.4 & 3 & 1.9 & 1 & 0.5 & 4 & 1.8 & NS & NS & NS \\
\hline $\begin{array}{l}\text { Monthly pill/ Chinese } \\
\text { pill }\end{array}$ & 7 & 1.2 & 0 & 0 & 6 & 3 & 1 & 0.4 & NS & NS & NS \\
\hline Male sterilization & 1 & 0.2 & 0 & 0 & 1 & 0.5 & 0 & 0 & NS & NS & NS \\
\hline $\begin{array}{l}\text { Emergency } \\
\text { contraception }\end{array}$ & 0 & 0 & 0 & 0 & 0 & 0 & 0 & 0 & NS & NS & NS \\
\hline
\end{tabular}

NS $=$ not sufficient

\section{Knowledge of the legal status of abortion}

In intervention arms, more women know that abortion is legal $(24 \%)$ than in the control arms $(7 \%)(p<0.001)$. In the combined intervention arm, significantly more women received information about the legal status of abortion from medical staff (30\%) than in the service delivery arm (18\%), $(\mathrm{p}<0.001)$ (Table 2).

\section{Knowledge of a place to obtain a safe abortion}

In the intervention arms, $88 \%$ of women said they know where to get safe abortion and $67 \%$ were able to name a safe abortion facility. In the control arm, $71 \%$ of women said they knew where to get safe abortion (Table 2). The proportion differs between the arms ( $\mathrm{p}<0.001)$ : In the combined intervention arm, more women were able to name a safe abortion facility $(86 \%)$ than in the service delivery arm (47\%). Women in the control arm were not able to name a safe abortion facility as these were not available in the provinces.

\section{Knowledge of timing and legal status of abortion}

On average, $96 \%$ of women know that the safest time for an abortion is during the first trimester. Seventy five percent of the respondents said any pregnancy could be legally ended if the health of the mother or the child is in danger with no difference between the three arms. Only $47 \%$ of the respondents thought that abortion was legal in cases of rape or incest. The percentage is significantly higher in the intervention arms (53\% on average) compared to the control arm $(36 \%)(\mathrm{p}<0.001)$. Only $21 \%$ of respondents said that any pregnancy could be legally ended during the first trimester. This percentage is lowest in the control arm $(13 \%)$ and increases in the service delivery arm $(21 \%)$ and 
more so in the combined intervention arm (30\%). The percentage is higher on average in the intervention arms $(27 \%)$ than in the control arm (13\%), $(\mathrm{p}<0.001)$ (Table 2).

\section{Knowledge of the risks of an unsafe abortion}

Severe bleeding and death were the two risks associated with unsafe abortion that women were aware of especially in the intervention arms. On average, 55\% of the respondents in the intervention arms were able to cite death as a possible consequence of an unsafe abortion, compared to $42 \%$ of women in the control arm $(\mathrm{p}<0.001)$. Fifty-nine percent of the respondents in the service delivery arm know that severe bleeding can occur after an abortion, compared to 53\% in the control arm ( $\mathrm{p}=0.04)$ (Table 2).

Table 2: Knowledge on Abortion.

\begin{tabular}{|c|c|c|c|c|c|c|c|c|c|c|c|}
\hline & \multirow{2}{*}{\multicolumn{2}{|c|}{$\begin{array}{c}\text { Total } \\
6 \text { Provinces }\end{array}$}} & \multirow{2}{*}{\multicolumn{2}{|c|}{$\begin{array}{c}\text { Control Arm } \\
\begin{array}{c}\text { Kampong } \\
\text { Som Pursat }\end{array} \\
\end{array}$}} & \multirow{2}{*}{\multicolumn{2}{|c|}{$\begin{array}{c}\begin{array}{c}\text { Service Delivery } \\
\text { (Arm A) }\end{array} \\
\begin{array}{c}\text { Siem Reap/ Prey } \\
\text { Veng }\end{array} \\
\end{array}$}} & \multirow{2}{*}{\multicolumn{2}{|c|}{$\begin{array}{c}\begin{array}{c}\text { Combined Intervention } \\
\text { (Arm B) }\end{array} \\
\text { Takeo/Kampong Thom }\end{array}$}} & \multicolumn{3}{|c|}{ Comparison Tests } \\
\hline & & & & & & & & & \multirow{2}{*}{$\begin{array}{c}\text { Control } \\
\text { vs. Arm A }\end{array}$} & \multirow{2}{*}{$\begin{array}{c}\text { Control } \\
\text { vs. Arm B }\end{array}$} & \multirow{2}{*}{$\begin{array}{l}\text { Arm A vs. } \\
\text { Arm B }\end{array}$} \\
\hline & $\mathbf{N}$ & $\%$ & $\mathbf{N}$ & $\%$ & $\mathbf{N}$ & $\%$ & $\mathbf{N}$ & $\%$ & & & \\
\hline $\begin{array}{l}\text { Aware of the legality of } \\
\text { abortion }\end{array}$ & 313 & 18.6 & 41 & 7.3 & 103 & 18.4 & 169 & 30.2 & $\mathrm{p}<0.001$ & $\mathrm{p}<0.001$ & $\mathrm{p}<0.001$ \\
\hline \multicolumn{12}{|c|}{ Source of information about the fact abortion is legal } \\
\hline Radio & 45 & 2.6 & 3 & 0.5 & 23 & 4.1 & 19 & 3.3 & $\mathrm{p}=0.001$ & $\mathrm{p}=0.003$ & NS \\
\hline $\begin{array}{l}\text { Medical staff at health } \\
\text { facility }\end{array}$ & 69 & 4 & 6 & 1.07 & 6 & 1 & 57 & 10.1 & NS & $\mathrm{p}<0.001$ & $\mathrm{p}<0.001$ \\
\hline Neighbours or friend & 77 & 4.5 & 15 & 2.6 & 29 & 5.1 & 33 & 5.8 & $\mathrm{p}=0.03$ & $\mathrm{p}=0.01$ & NS \\
\hline Village health volunteer & 38 & 2.2 & 3 & 0.5 & 14 & 2.5 & 21 & 3.7 & $\mathrm{p}=0.01$ & $\mathrm{p}=0.01$ & NS \\
\hline NGO at the village & 25 & 1.4 & 3 & 0.5 & 6 & 1 & 16 & 2.8 & NS & $\mathrm{p}=0.007$ & $\mathrm{p}=0.03$ \\
\hline $\begin{array}{l}\text { Knowledge of place for } \\
\text { safe abortion }\end{array}$ & 1,385 & 82.4 & 398 & 71.1 & 487 & 87 & 500 & 89.3 & $\mathrm{p}<0.001$ & $\mathrm{p}<0.001$ & NS \\
\hline \multicolumn{12}{|c|}{ Situations allowing abortion } \\
\hline $\begin{array}{l}\text { Any pregnancy during } \\
\text { the 1st trimester }\end{array}$ & 359 & 21.4 & 72 & 12.9 & 119 & 21.3 & 168 & 30.1 & $\mathrm{p}<0.001$ & $\mathrm{p}<0.001$ & $\mathrm{p}=0.002$ \\
\hline $\begin{array}{c}\text { Pregnancy after rape or } \\
\text { incest }\end{array}$ & 790 & 47 & 202 & 36.1 & 279 & 49.8 & 309 & 55.2 & $\mathrm{p}<0.001$ & $\mathrm{p}<0.001$ & NS \\
\hline $\begin{array}{l}\text { Health issues for mother } \\
\text { or child }\end{array}$ & 1,265 & 75.3 & 420 & 75 & 413 & 73.8 & 432 & 77.1 & NS & NS & NS \\
\hline \multicolumn{12}{|c|}{ Knowledge on risks of unsafe abortion } \\
\hline Severe bleeding & 944 & 56.1 & 299 & 53.3 & 332 & 59.2 & 313 & 55.8 & $\mathrm{p}=0.047$ & NS & NS \\
\hline Death & 841 & 50 & 237 & 42.3 & 282 & 50.3 & 322 & 57.5 & $\mathrm{p}=0.007$ & $\mathrm{p}<0.001$ & $\mathrm{p}=0.01$ \\
\hline Undefined risks & 499 & 29.7 & 180 & 32.1 & 172 & 30.7 & 147 & 26.3 & NS & $\mathrm{p}=0.03$ & NS \\
\hline Infection & 162 & 9.6 & 46 & 8.2 & 61 & 10.8 & 55 & 9.8 & NS & NS & NS \\
\hline Infertility & 36 & 2.1 & 14 & 2.5 & 7 & 1.2 & 15 & 2.6 & NS & NS & NS \\
\hline Do not know any risk & 37 & 2.2 & 21 & 3.75 & 9 & 1.6 & 7 & 1.2 & $p=0.03$ & $\mathrm{p}=0.01$ & NS \\
\hline
\end{tabular}

\section{Induced abortion}

Overall, $17 \%$ of the women interviewed who wanted to have an abortion were not able to mainly due to fear of health side effects (24\%), husband not agreeing (23\%) and lack of funds (21\%). There was no significant difference between the arms. Among the 134 women who said they had at least one induced abortion, the average number of abortions per woman was 1.4 in their lifetime with no difference between the arms; $97 \%$ of the last pregnancy terminations were during the first trimester, $3 \%$ were terminated during the second trimester and no pregnancy was terminated during the third trimester. Most of the women (average 64\%) go to a private facility for an abortion, although this is less usual in the combined intervention arm (48\%) than in the service delivery or control arms (72\%), ( $\mathrm{p}=0.002)$ In the combined intervention arm, $32 \%$ of the women went to a public facility for their last abortion versus $7 \%$ in service delivery arm $(\mathrm{p}=0.002)$.

\section{Methods of induced abortion}

Of the women who had an abortion, 63\% reported their pregnancy was terminated using manual vacuum aspiration (MVA); 22\% reported their pregnancy was aborted using medical abortion pills and $9 \%$ reported the dilation and curettage method 


\section{Global Journal of Reproductive Medicine}

was used (Table 3). The proportion of women who said they had taken abortion pills is higher in the combined intervention arm

(31\%) than in the two other arms though this is not statistically significant.

Table 3: Induced Abortion Services.

\begin{tabular}{|c|c|c|c|c|c|c|c|c|c|c|c|}
\hline \multirow{3}{*}{$\begin{array}{l}\text { Among women who had } \\
\text { at least } 1 \text { abortion }\end{array}$} & \multirow{2}{*}{\multicolumn{2}{|c|}{$\begin{array}{c}\text { Total } \\
6 \text { Provinces }\end{array}$}} & \multirow{2}{*}{\multicolumn{2}{|c|}{$\begin{array}{c}\text { Arm control } \\
\begin{array}{c}\text { Kampong Som/ } \\
\text { Pursat }\end{array}\end{array}$}} & \multirow{2}{*}{\multicolumn{2}{|c|}{$\begin{array}{c}\begin{array}{c}\text { Service Delivery } \\
\text { (Arm A) }\end{array} \\
\begin{array}{c}\text { Siem Reap/ Prey } \\
\text { Veng }\end{array}\end{array}$}} & \multirow{2}{*}{\multicolumn{2}{|c|}{$\begin{array}{c}\text { Combined } \\
\text { Intervention (Arm B) } \\
\begin{array}{c}\text { Takeo/ Kampong } \\
\text { Thom }\end{array}\end{array}$}} & \multicolumn{3}{|c|}{ Comparison Tests } \\
\hline & & & & & & & & & \multirow{2}{*}{$\begin{array}{c}\text { Control } \\
\text { vs. Arm A }\end{array}$} & \multirow{2}{*}{$\begin{array}{l}\text { Control vs. } \\
\text { Arm B }\end{array}$} & \multirow{2}{*}{$\begin{array}{l}\text { Control } \\
\text { vs. Arm } \\
\text { B }\end{array}$} \\
\hline & $\mathrm{N}=134$ & $\%$ & $\mathrm{~N}=43$ & $\%$ & $\mathrm{~N}=44$ & $\%$ & $\mathrm{~N}=47$ & $\%$ & & & \\
\hline Had more than 1 abortion & 36 & 26.7 & 16 & 37.2 & 11 & 25 & 9 & 18.8 & NS & $\mathrm{p}=0.052$ & NS \\
\hline $\begin{array}{c}\text { Last abortion was in } \\
2009 / 2010\end{array}$ & 30 & 22.2 & 11 & 25.6 & 9 & 20.5 & 10 & 20.8 & NS & NS & NS \\
\hline \multicolumn{12}{|c|}{ Term in which abortion took place } \\
\hline 1rst trimester & 130 & 97 & 41 & 95.3 & 44 & 100 & 45 & 95.7 & NS & NS & NS \\
\hline 2nd trimester & 4 & 3 & 2 & 4.7 & 0 & 0 & 2 & 4.2 & NS & NS & NS \\
\hline 3rd trimester & 0 & 0 & 0 & 0 & 0 & 0 & 0 & 0 & NS & NS & NS \\
\hline \multicolumn{12}{|c|}{ Method used to end last pregnancy } \\
\hline $\begin{array}{l}\text { Manual vacuum } \\
\text { aspiration }\end{array}$ & 81 & 63.3 & 29 & 72.5 & 31 & 72.1 & 21 & 46.7 & NS & $\mathrm{p}=0.02$ & $\mathrm{p}=0.009$ \\
\hline Medical abortion pills & 28 & 21.9 & 6 & 15 & 8 & 18.6 & 14 & 31.1 & NS & $\mathrm{NS}(\mathrm{p}=0.08)$ & NS \\
\hline Curettage & 12 & 9.4 & 2 & 5 & 2 & 4.7 & 8 & 17.8 & NS & NS & $\mathrm{p}=0.052$ \\
\hline Other & 2 & 1.6 & 0 & 0 & 1 & 2.3 & 1 & 2.2 & NS & NS & NS \\
\hline Do not know or missing & 17 & 3.9 & 9 & 7.5 & 3 & 2.3 & 3 & 2.2 & NS & NS & NS \\
\hline \multicolumn{12}{|c|}{ Place of abortion } \\
\hline Private clinic or hospital & 86 & 63.7 & 28 & 65.1 & 35 & 79.6 & 23 & 47.9 & NS & NS & $p=0.002$ \\
\hline Public facility & 26 & 19.4 & 8 & 18.6 & 3 & 6.8 & 15 & 31.9 & NS & NS & $\mathrm{p}=0.003$ \\
\hline Nowhere, did it alone & 15 & 11.1 & 4 & 9.3 & 5 & 11.4 & 6 & 12.5 & NS & NS & NS \\
\hline Missing & 8 & 5.9 & 3 & 7 & 1 & 2.3 & 3 & 8.3 & NS & NS & NS \\
\hline Total & 134 & 100 & 43 & 100 & 44 & 100 & 47 & 100 & NS & NS & NS \\
\hline \multicolumn{12}{|c|}{ Provider of the abortion * in some case, multiple providers helped the woman } \\
\hline Doctor & 23 & 17.2 & 13 & 30.2 & 7 & 15.9 & 3 & 6.4 & NS & $\mathrm{p}=0.007$ & NS \\
\hline Medical assistant & 16 & 11.9 & 3 & 7 & 4 & 9.1 & 9 & 19.2 & NS & NS & NS \\
\hline Midwife & 85 & 63.4 & 24 & 55.8 & 30 & 68.2 & 31 & 66 & NS & NS & NS \\
\hline Nurse & 0 & 0 & 0 & 0 & 0 & 0 & 0 & 0 & NS & NS & NS \\
\hline TBAs & 2 & 1.5 & 1 & 2.3 & 0 & 0 & 1 & 2.1 & NS & NS & NS \\
\hline Elder in the village & 3 & 2.4 & 1 & 2.5 & 0 & 0 & 2 & 4.4 & NS & NS & NS \\
\hline Nobody, did it alone & 12 & 8.9 & 2 & 4.7 & 3 & 6.8 & 7 & 14.6 & NS & NS & NS \\
\hline \multicolumn{12}{|c|}{ Contraceptive services } \\
\hline $\begin{array}{l}\text { Staff gave counselling on } \\
\text { contraception }\end{array}$ & 87 & 65.9 & 21 & 50 & 35 & 79.6 & 31 & 67.4 & $\mathrm{p}=0.005$ & NS & NS \\
\hline $\begin{array}{l}\text { Staff suggested } \\
\text { contraceptives }\end{array}$ & 88 & 66.7 & 21 & 50 & 32 & 72.7 & 35 & 76.1 & $\mathrm{p}=0.03$ & $\mathrm{p}=0.01$ & NS \\
\hline
\end{tabular}

\section{Use of Safe abortion facilities}

Most women (87\%) were assisted by a trained provider for their last abortion; $80 \%$ from a midwife, $16 \%$ from a doctor and $12 \%$ from a medical assistant. In the intervention arms, the proportion of women using safe abortion facilities is similar: $58 \%$ of the women who had an abortion in the past three years used a safe facility. Half of the women who went to safe abortion facilities knew the name of the provider and these were all registered as trained providers.

\section{Women's perception on the quality of abortion care}

A higher number of women in the intervention arms reported receiving clear information on the abortion procedure beforehand (69\%) than in the control arm (32\%). Also, a greater number of women said they received information about potential 


\section{Global Journal of Reproductive Medicine}

complications after the abortion in the service delivery arm (84\%) than in the control arm (60\%).

\section{Contraception after abortion}

On average, $66 \%$ of the women said they received information on contraceptives immediately after their last abortion. The performance of medical staff in the service delivery arm is better, with $80 \%$ of women reporting having received information. In both intervention arms, $75 \%$ of the women were referred to get a contraceptive method after the last abortion, compared with $50 \%$ in the control arm.

\section{Use of contraceptive method after an abortion}

There is no significant difference between the arms in the current use of contraceptive method after an abortion. The daily pill is the most commonly used (33\% of all women). Injectables are used by $21 \%$ of women while $10 \%$ use the rhythm method and another $10 \%$ use male condoms.

\section{Discussion and Conclusion}

Findings from the study show significant differences in the provinces where RMMP implemented activities compared to control areas. Women in the intervention provinces are more aware and have more knowledge of contraceptive methods and safe abortion practices. In service delivery areas, health providers did significantly better in providing information on various contraceptive methods. This finding aligns to other studies in Cambodia where health provider attitudes influenced clients' intention to use health services, more so than physical and financial barriers $[7,8]$. Training providers in reproductive health care, particularly midwives and medical assistants who by law are allowed to provide surgical abortion until 12 weeks gestation had an immense impact in RMMP supported provinces [9]. Evidence suggests that mid-level providers working in remote areas, are either already providing medical abortion or have the skills to adminster this already. With some additional training, access to quality reproductive health services can be greatly improved $[10,11]$.

A significant number of women are going to health centers for a contraception method in provinces where RMMP interventions were implemented. Women in intervention provinces are more informed about contraceptive methods and side effects and are more likely to use a method properly. This complements another study in Cambodia which showed increased contraceptive use once women had better knowledge and access to methods [12]. Significantly more women in the intervention areas are informed of the legal status of abortion, having received information about this from health providers. Almost all women knew that the safest time for an abortion is during the first trimester and that any pregnancy could be legally ended if the health of the mother or the child is in danger. This finding confirms evidence suggesting that both providers and women need to be educated about the legal status of and where to access safe abortion and contraception services [13]. Legalization of abortion has had a positive effect in other countries including in South Africa [14], Guyana and Nepal where morbidity and mortality due to unsafe abortion was reduced $[15,16]$. While legalization of abortion is a major step forward, access to skilled care and safe abortion methods are essential to reducing the burden of unsafe abortion and maternal mortality as well as improving women's health more broadly [17].

Abortion by MVA is most commonly used followed by medication abortion. Curettage is less used and often provided in the informal sector. An earlier 2007 study however showed that curettage was the most common method for performing abortions in Cambodia [18], suggesting that there have been improvements in the roll out of MVA and medical abortion [19]. Women in intervention areas reported receiving clear information on the abortion procedure beforehand and on possible complications after the procedure. More women in intervention areas know where to find a safe abortion provider. Most of the women were referred for contraceptive services after their last abortion. Another study in Cambodia suggested increased contraceptive use after the implementation of safe abortion services [20]. Accelerating interventions to improve access to safe abortion and contraceptive services will be essential for Cambodia to improve health and achieve its Sustainable Development Goals [7,21].

\section{References}

1. World Health Organization (2015) Success factors for women's and children's health Cambodia. Geneva, Switzerland.

2. Fordham G (2003) Adolescent and youth reproductive health in Cambodia: Status, issues, policies and programs: Policy project.

3. National Institute of Statistics (2015) Directorate General for Health. ICF International. Cambodia Demographic and Health Survey 2014. Phnom Penh Cambodia and Rockville Maryland USA: National Institute of Statistics, Directorate General for Health, and ICF International.

4. Liljestrand J, Sambath MR (2012) Socio-economic improvements and health system strengthening of maternity care are contributing to maternal mortality reduction in Cambodia. Reprod Health Matters 20(39): 62-72.

5. Fetters T, Vonthanak S, Picardo C, Rathavy T (2008) Abortion-related complications in Cambodia. BJOG 115(8): 957-968.

6. Lavoisier E, Isaakidis P, Goyet S, Hancard Peitet P, Bandali S, et al. (2010) Household survey for the reduction in maternal mortality project: Evaluation of service provision and community mobilisation activities Options Consultancy Services and SBK Research and Development.

7. Takahashi Y, Chuemchit M (2016) Knowledge, Attitudes and Practices (KAP) of birth preparedness and complication readiness in relation to skilled birth attendant among delivered women in Svay Rieng province, Cambodia. Journal of Health Research 30(Suppl.1): S35-44.

8. Matsuoka S, Aiga H, Rasmey LC, Rathavy T, Okitsu A (2009) Perceived barriers to utilization of maternal health services in rural Cambodia. Health Policy 95(2-3): 255-263.

9. Long C, Ren N (2001) Abortion in Cambodia: country report. Expanding access: advancing the roles of midlevel providers in menstrual regulation and elective abortion care. South Africa Ipas.

10. Yarnall J, Swica Y, Winikoff B (2009) Non-physician clinicians can safely provide first trimester medical abortion. Reproductive Health Matters 17(33): 61-69. 
11. Berer M (2009) Provision of abortion by mid-level providers: international policy, practice and perspectives. Bulletin of the World Health Organization 87: 58-63.

12. Hukin E (2014) Cambodia's fertility transition: The dynamics of contemporary childbearing. Population and Development Review. 40(4): 605-628.

13. Haddad LB, Nour NM (2009) Unsafe abortion: Unnecessary maternal mortality. Rev Obstet Gynecol 2(2): 122-126.

14. Jewkes R, Rees H, Dickson K, Brown H, Levin J (2004) The impact of age on the epidemiology of incomplete abortions in South Africa after legislative change. BJOG 112(3): 355-359.

15. Nunes FE, Delph YM (1997) Making abortion law reform work: steps and slips in Guyana. Reproductive Health Matters 5(9): 66-76.

16. (2017) Center for Research on Environment Health and Population Activities. Abortion and unintended pregnancy in Nepal: Guttmacher Institute.
17. Grimes DA, Benson J, Singh S, Romero M, Ganatra B, et al. (2006) Unsafe abortion: the preventable pandemic. Lancet 368(9550): 1908-1919.

18. Rathavy T, Fetters T, Sherman J, Vonthanak S, Phirun L (2007) 'Ready or not?' A national needs assessment. Chapel Hill, North Carolina: Ipas.

19. Singh S (2006) Hospital admissions resulting from unsafe abortion: estimates from 13 developing countries. Lancet 368(9550): 18871892.

20. Delvaux T, Soeur S, Rathavy T, Crabbé F, Buvé A (2008) Integration of comprehensive abortion-care services in a maternal and child health clinic in Cambodia. Trop Med Int Health 13(8): 962-969.

21. Cleland J, Bernstein S, Ezeh A, Faundes A, Glasier A, et al. (2006) Family planning: the unfinished agenda. Lancet 368(9549): 1810-1827.

Your next submission with Juniper Publishers
will reach you the below assets
- Quality Editorial service
- Swift Peer Review
- Reprints availability
- E-prints Service
- Manuscript Podcast for convenient understanding
- Global attainment for your research
- Manuscript accessibility in different formats
( Pdf, E-pub, Full Text, Audio)
- Unceasing customer service
Track the below URL for one-step submission
https://juniperpublishers.com/online-submission.php

